\title{
Cuerpo, orden colonial e historia: entrevista a Alejandra Araya
}

\section{THE BODY, COLONIAL RULE, AND HISTORY: Interview With Alejandra Araya}

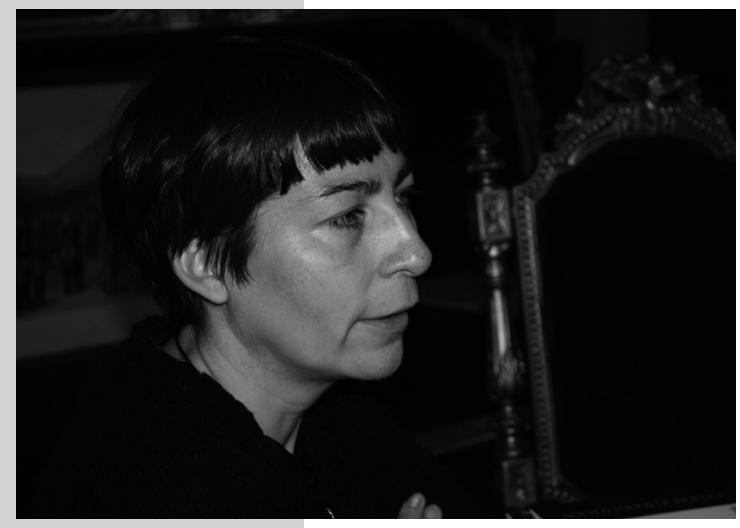

Es el 19 de agosto en el segundo piso del Archivo Andrés Bello, en la oficina de Alejandra Araya, su directora. Alejandra es una historiadora del cuerpo en la Capitanía General: una historia colonial del cuerpo, pero también una historia presente. De ese cuerpo que creemos captar mediante el manejo numérico de la salud pública, pero que aparece siempre dispuesto a sorprendernos. Doble sorpresa esta vez, si ese cuerpo nos habla por la boca de una historiadora empeñada en leer sentidos, a partir de los signos e inscripciones que el azote ha dejado allí. Este texto es una pequeña parte de una conversación con té y aromas, entre libros y retratos, en el ala oriente de nuestra casa central

La primera pregunta es ¿tú eres doctorada en el colegio de México, eres historiadora, eres directora del archivo Andrés Bello, pero abora desarrollas un proyecto sobre el cuerpo en la capitanía general, no como período bistórico sino como un lugar?

¿Por dónde iniciar? Voy a partir por lo último que planteaste sobre lo colonial. En la Universidad de Chile y en particular, en mi formación, sigo una línea historiográfica que es la historia de las mentalidades. De allí derivo al cuerpo. Pero mi trayectoria está asociada a un historiador que fue Rolando Mellafe. Por él me interesó la historia colonial. Una tradición historiográfica en la Universidad de Chile que abrió en la década de los

Yuri Carvajal* Escuela de Salud Pública Facultad de Medicina Universidad de Chile ycarvajal@uchile.cl

\section{Miguel Kottow}

Escuela de Salud Pública Facultad de Medicina Universidad de Chile mkottow@gmail.com cincuenta la pregunta por lo colonial, desde un lugar que era pionero, y que se interrogaba por aquello que era más significativo para la experiencia de los sujetos; él, junto con Álvaro Jara se hicieron las preguntas por las personas, incluso desde un lugar muy técnico como es la demografía. En

\footnotetext{
* El autor agradece el apoyo del Conicyt a través del Fondecyt de Postdoctorado 3130585 "Controversias tecno-científicas en la reforma de salud: análisis desde la sociología de la traducción”.
} 
esas primeras investigaciones ya hay una pregunta por los cuerpos de quienes estaban aquí antes de la llegada de los españoles, cuántos eran (el peso del número para calibrar uno de los elementos importantes de la llamada leyenda negra de la conquista, que era el despoblamiento), cómo responder a la pregunta por la disminución de la población indígena, pero de otro lado cómo decir quiénes éramos en esta sociedad colonial, más allá de las instituciones. El mismo Rolando Mellafe se preocupó en su tesis sobre la introducción de la esclavitud negra en Chile -tema que en esa época la verdad es que no era considerado. $\mathrm{Su}$ propio profesor guía, que fue Guillermo Félix Cruz, le decía, "bueno y para qué saber de los negros”. Mellafe se metió en los archivos notariales viendo las partidas de ingresos de venta de los esclavos y a partir de un documento que podríamos decir muy frío, instala la presencia de una población sobre la cual nosotros no teníamos elaborado un discurso, un relato y una memoria. Hasta ahora es difícil, pero esa instalación que hace Rolando Mellafe ha tenido su trayectoria en la propia Universidad de Chile, y hoy dirijo un estudio de grupos coloniales en la Universidad que sigue estas herencias, que son interdisciplinarias, más sociales y culturales y en diálogo con lo que se llama las teorías de la colonialidad y de la poscolonialidad.

Lo colonial ya no es un periodo, volviendo a tu pregunta inicial. Hablo de la Capitanía General de Chile para instalar una cierta ubicación temporal, pero en la que para mí hay una permanencia, una latencia, de esa experiencia colonial que todavía es operativa en nuestra sociedad.

A propósito del proyecto, esta semana presento una ponencia que va a ser un artículo, sobre los azotes en Chile. De qué manera, me pregunto, se coloniza un imaginario partiendo de esa propuesta o de esa hipótesis. Los imaginarios se transforman también, no solamente las personas en sí mismas. Finalmente el resultado más denso y el que cuesta más modificar es la transformación de los imaginarios. ¿Cómo se modifican tus concepciones del cuerpo partiendo por la noción de cuerpo y los castigos físicos? Uno no podría partir de una noción biológica del cuerpo, en la que cualquier afección es dolorosa; es importante poner en juego que no todo te duele de la misma manera en determinadas culturas y sociedades y tiempos históricos. Que eso tiene unos límites, unas fronteras que son construcciones culturales también, lo que no quiere decir que sean de libre interpretación, pero que son un problema. El caso del azote me quedó dando vueltas desde que hice una investigación sobre los ociosos, los vagabundos y los malentretenidos, en que abordé el disciplinamiento social. En este caso, el principal castigo era el azote. Me preguntaba por las marcas de identidad del azote, pues el azote implica una nueva pregunta sobre la historia del cuerpo y la colonización del imaginario desde esta herida colonial. Lo trabajo como una herida colonial y tomo esas metáforas de las heridas físicas para señalar que hay un marca; a partir de una experiencia en lo colonial hay confrontación sobre concepciones del cuerpo distintas y prácticas específicas sobre el cuerpo. Aquí hay un castigo, que para la experiencia europea existe, pero que en lo que he rastreado, en las sociedades indígenas no se da un castigo de esta naturaleza. No quiero decir que no haya obviamente aflicción hacia el cuerpo, pero esa aflicción tiene una semántica, una significación distinta de acuerdo a las sociedades y las culturas. No todo duele de la misma manera ni a todos les duele de la misma manera.

La instalación del azote como una forma de castigo de disciplinamiento, de corrección tuvo un lugar central, como signo: el abuso del azote, el signo del abuso colonial. Hay muchas imágenes del abuso colonial, la opresión y el despotismo en torno al azote. El azote en Chile se elimina en 1949 como pena y se elimina en las instituciones correccionales, en los colegios, en las instancias de educación pedagógica y va a desaparecer recién con Gabriel González Videla, un año después de la Ley Maldita. Hay unos juegos importantes desde el punto de vista de los imaginarios sobre las formas del ejercicio del poder, en el azote como un espacio de reflexión, pero también como una práctica concreta.

El azote traspasa las instituciones norma- 
tivas de todo el siglo XIX y de la primera del $\mathrm{XX}$, cuando se torna una discusión pública, legal e institucional, ya tiene que ver con los derechos de los hombres y los ciudadanos en los discursos ilustrados y republicanos. Ellos instalan una discusión global sobre la necesidad de eliminar, como parte de la justicia, castigos que finalmente son injustos, que son contraproducentes respecto de lo que la justicia debe conseguir. Pero porque también existe una sensibilidad distinta sobre el sufrimiento físico que tiende por ejemplo a eliminar del espacio público y del espectáculo público -como mencionaba Michel Foucault-, este tipo de escarmiento. Pero también de las prácticas cotidianas asociadas al derecho de los padres o de cualquier autoridad que se instala como la figura de lo paterno. Los padres de familia tenían el derecho a golpear al otro, a azotarlo. Azote significa, por una parte, el golpe dado con un instrumento particular de ese nombre. Pero por otro, es el azote que da el padre a sus hijos con la mano abierta. Es decir, tiene una serie de metáforas sobre la forma de golpear y de corregir que es muy importante. Eso es lo que desde mi perspectiva sigue permaneciendo, no obstante que se acabe en teoría lo colonial, hasta muy entrado el siglo XX. Y estoy segura de que es una práctica que todavía sigue, y si tú quieres una tercera vía, que es la del sadismo o la de los abusos, en todas sus formas, están allí todavía.

\section{¿Y qué pasa con los indios?}

Esa es la parte más compleja respecto al proyecto, porque es difícil. La sociedad chilena tiene borrada culturalmente su pertenencia a un mundo indígena, y eso lo vuelve muy difícil rastrear. Podría decir -estoy partiendo de esta hipótesis y hasta ahora nadie me ha dicho lo contrario-, que ese tipo de castigo en particular no existe en las sociedades indígenas. Hay desmembramiento, hay decapitación, pero azote en particular, como forma de humillación y de corrección en público, no. Eso es lo que a mí me parece importante rescatar y por eso hablo de una colonización de lo ima- ginario y del impacto que puede haber producido eso. Lo puedes rastrear en las denuncias por maltrato de indios por sus encomenderos o encomenderas. Es el caso de la Quintrala o de los esclavos por sevicia, la crueldad excesiva. Cuando uno habla de colonización del imaginario a partir de las propuestas de Gruzinski, estamos pensando en qué tipo de elementos pueden haber funcionado como traductores de culturas diferentes. Aunque las prácticas o los gestos no hayan sido las mismas, en el fondo tienen una similitud en el hacer. El azote instala una ruptura, por lo tanto en el proyecto lo más difícil va a ser generar las metodologías y las estrategias para poder dar cuenta del otro lado.

Cómo se reflexiona y qué es lo que puede haber quedado a nivel de los mitos, de las leyendas entre comillas, de una cierta memoria quizá oral. Eso lo estamos trabajando en tres perspectivas: el que estoy revisando, el de los cuerpos y los castigos, con Constanza Acuña, filóloga, [con quien] estamos haciendo un trabajo con las referencias que hay para las gramáticas y diccionarios de la época de mapudungun al español y al latín, en particular el texto del padre Havestadt, jesuita, el que se conoce para el caso mapuche de fines del siglo XVIII como un diccionario. En el segundo enfoque, sobre las partes del cuerpo, podemos contrastar los resultados con la propuesta que hace Alfredo López Austin para el caso mexicano. Estamos trabajando con la noción de cosmovisión, cómo introducir ese concepto para poder pensar las concepciones del cuerpo dentro de una cosmovisión mapuche, si es pertinente decirlo o no. Y rastrearlo a partir de los términos con los cuales se empezó a traducir esas concepciones del cuerpo occidental con el mundo mapuche; por eso la lengua es una de las alternativas.

Y la tercera vía es propiamente la médica. Paulina Zamorano está trabajando en eso con los registros del Hospital San Borja que están en el Museo Nacional de Historia de la Medicina de la Universidad de Chile. Son registros de mujeres. ¿Cuál es la pregunta allí? ¿Cuál es el lenguaje para dar cuenta del dolor? Porque sabemos que la terminología más científica o médica de las enfermedades es muy reciente. 
Eso también lo exploré en mi tesis doctoral, a través de las cartas de una monja, en torno a la enfermedad. Se trata de un lenguaje mucho más descriptivo y metafórico, que no está anclado en la idea positiva de un síntoma "verdadero" de las enfermedades. Es otro mundo, que recurre al mundo religioso y a su experiencia mística, para dar cuenta de un estado de normalidad, que se dice enfermo o no. $\mathrm{O}$ que se grafica en la palabra enfermo, me siento enfermo, estoy enfermo. Paulina está explorando con estos registros de las enfermas. ¿Quién describe?¿Quién dice el padecimiento? ¿Cómo se dice? Y estamos explorando cosas bien interesantes. ¿Qué partes del cuerpo son las que se describen? Por ejemplo tú me dices, no hay mujeres, solo hombres en los castigos. Por supuesto que es masculino, porque tiene que ver con el poder. $¿$ Quien ejerce el poder y la autoridad y dónde? ¿En qué espacio? Pero si vas al registro de los hospitales, que en este caso es de mujeres, obviamente se trata de un cuerpo femenino. En los castigos hay espaldas, brazos, cuerpo entero, partes blandas. En el caso de las mujeres es útero, es tronco. Pero no hay cabeza, no hay extremidades. Te vas haciendo unas cartografías de los lugares del cuerpo, de los lugares de enunciación de ese cuerpo en los documentos como instrumento público, en el sentido que instalan una esfera que no es ya la de lo personal, un lenguaje y una manera de decir en qué lugares y en qué circunstancias es viable hablar del cuerpo y de qué cuerpo. Porque puedes encontrar superposiciones de imágenes y concepciones. Volviendo a la propuesta de la historia de las mentalidades operan en un mismo tiempo, tradiciones que van desde el medievo hasta las sociedades prehispánicas y actualizaciones en torno a debates puntuales de la política.
Es una cuestión muy fascinante, pero además de fascinante, muy crucial para pensar por ejemplo en la modernidad. ¿De qué tipo de modernidad estamos hablando a partir de las concepciones del cuerpo y la experiencia del cuerpo? ¿Qué cuerpo es éste en las discusiones sobre la enfermedad y las formas de decir? En estos registros, la gente va a morir al hospital. Se recupera una figura del hospital como hospicio, hospitalidad. Esa es la conexión, porque se supone que se va a morir. Así como se hacía el testamento cada vez que se sentían enfermos y pensaban que se iban a morir. Porque era una posibilidad muy real. Por lo tanto, el lenguaje es del padecimiento muy religioso, en una persona que siente que está al borde de la muerte. No es técnico, su objetivo es producir conmiseración. ¿Con qué sentido se hace el relato? Porque el que hace los registros -según lo que ya ha investigado Paulina- es un párroco en el hospital. Y lo hace para ver si le tiene que dar la extremaunción o no. Es una lógica bien distinta a la que hoy opera en el espacio médico o la medicalización del cuerpo en el mundo más contemporáneo. El lenguaje incide en la experiencia de la corporalidad de los sujetos. ¿Cómo tú pueblas tu propio cuerpo de los imaginarios médicos actuales al hablar de enfermedad? “Depresión", por ejemplo, con esta palabra vas incorporando una manera de decir tu estado físico, que tiene que ver con el lenguaje médico, sin que eso corresponda necesariamente al diagnóstico clínico. Pero está funcionando socialmente y eso modifica tu concepción de ti mismo como individuo. Y ahí la parte más compleja en el proyecto puntual es hasta qué punto vamos a poder dar cuenta o al menos instalar, las preguntas sobre el cuerpo del Otro. 